\title{
POMPILID WASPS AND PREY-TRANSPORTATION BY WATER
}

\author{
BY PHIL RAU \\ Kirkwood, Mo.
}

One of the most interesting items of wasp behavior is reported by Needham and Lloyd $d^{1}$ on the use of water as a medium for the easy transportation of spider prey by Priocnemis flavicornis. This Pompiled wasp was occasionally seen on Fall Creek, New York, where it combines flying and water transportation.

"Beavers swim with boughs for their dam, and waterstriders run across the surface carrying their booty, but there is a wasp that flies above the surface towing a load too heavy to be carried. The freight is the body of a huge black spider several times as large as the wasp. It is captured by the wasp in a waterside hunting expedition, paralized by a sting adroitly placed, and is to be used for provisioning the nest. It could scarcely be dragged across the ground, that is with the dense vegetation of the waterside; but the placid stream is an open highway. Out into the surface the wasp drags the huge limp, black carcass of the spider, and, mounting into the air with her engines going and her wings steadily buzzing, she sails away across the water, trailing the spider, and leaving a wake that is a miniature of a passing steamer. She sails a direct and unerring course to the vicinity of her burrow in the bank, and brings her cargo ashore at some nearby landing. She hauls it upon the bank and then runs to her hole to see that all is ready. Then she drags the spider up to the bank and into her burrow, having so saved much time and energy by making use of an open waterway."

It would seem from the records that this highly intelligent behavior is an isolated case; therefore the purpose of this note is to record three similar instances of this singular behavor. It is however to be regretted that in all three cases was it impossible to get either Pompilid or spider for identification.

${ }^{1}$ Life on Inland Waters, page $331,1916$. 
In 1915 on the water near the shore of a lake at Lakeview, Kansas, a Pompiled and her spider were seen behaving in the same way as described above but at that time I was a novice in waspology and did not fully appreciate the drama that was being enacted before me. I thought at the time that both had fallen from the branches overhead, and the wasp was trying to regain the shore. In 1919 at Wickes, Missouri, my wife saw the same behavior on the surface of a small pond, but not having a net was unable to capture the pair; but knowing of Needham and Lloyd's account by this time she was fully prepared to appreciate the behavior.

And the third observation was made by Dr. Gustave Dahms, an ardent fisherman, who pays much attention to nature study. Here is his account as he related it to me:

On July 20th, 1932, while watching his cork bob in the stream near Creve Couer Lake, Mo., he saw a black wasp towing a spider twice as large as herself on the surface of the water. Straddling her spider, she looked like an aquaplane, while she made a distance of six feet to the wooden pillar in the water supporting a railroad trestle. Landing on this pillar, she moved upwards and backwards dragging her spider after her to the top of the trestle, and then disappeared. There was soil packed in between the railroad ties at the edges, and in this she evidently buried her spider. Most interesting of all was the fact that between 10:30 and 2:00 o'clock while this fisherman was watching his bob, this behavior was repeated four times with hardly any variation in her course, in relation to this bob. The trip, as he enthusiastically explained, was purposeful each time, and the distance of ten feet of travel in the water from the bob where he always first noticed the wasp to the post on which she clmibed consumed only about one minute, so fast did she sail. There was a slight current in her direction which helped her to make speed. Unfortunately he paid no attention from whence she came, but saw her each time as she neared the bob. Unfortunately too he did not get the specimen for identification and he never found out whether all four spiders went into one burrow or into four burrows. 

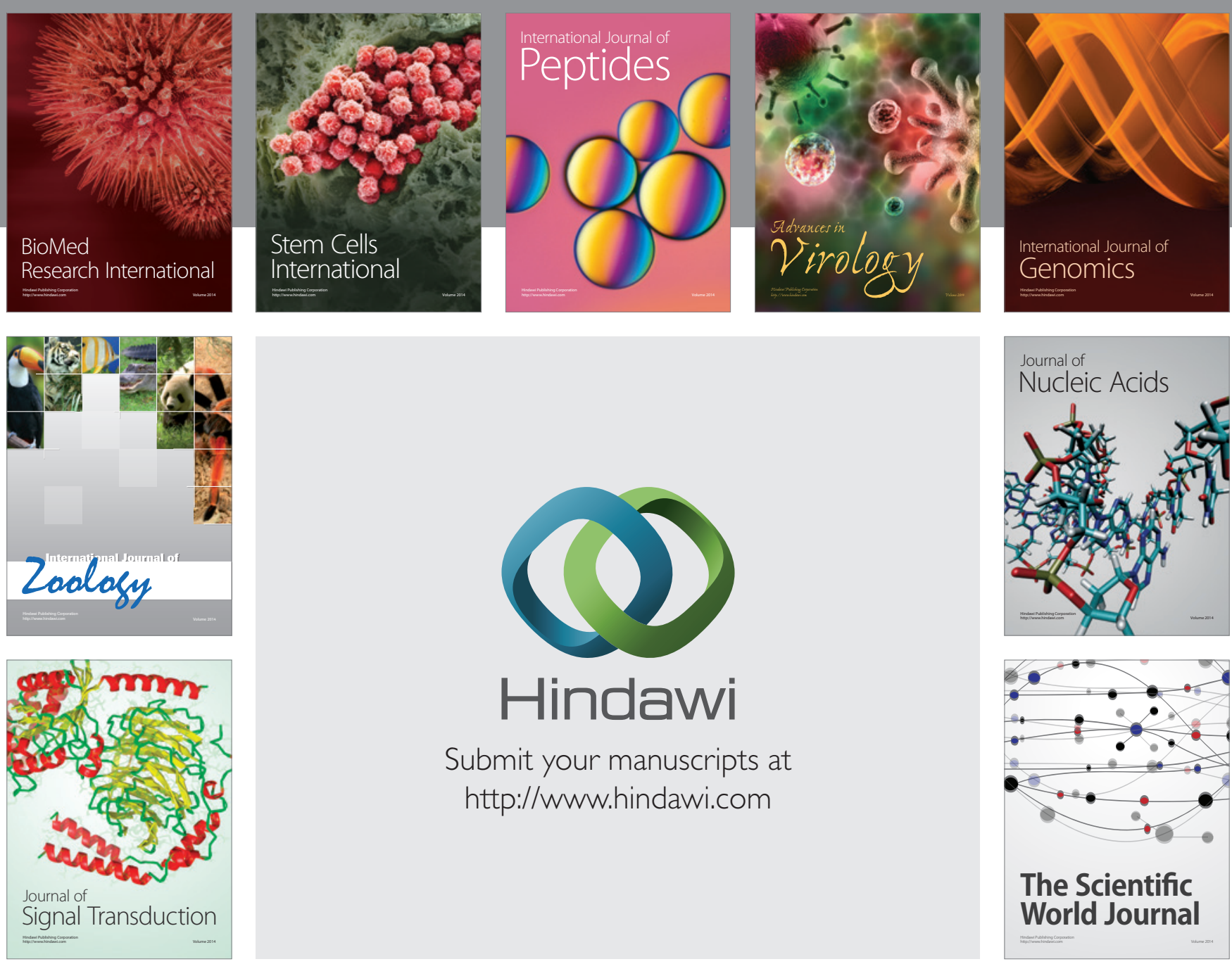

Submit your manuscripts at

http://www.hindawi.com
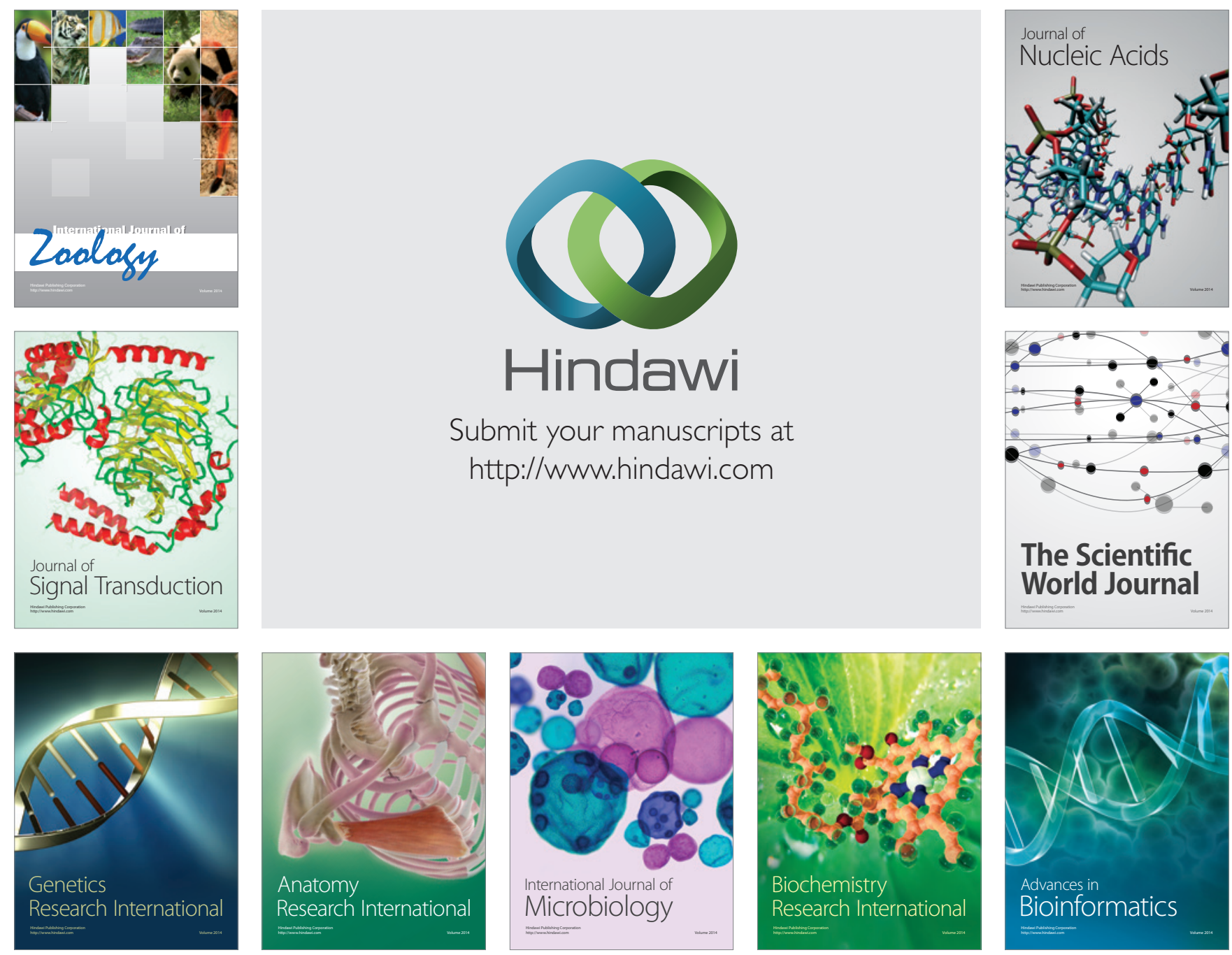

The Scientific World Journal
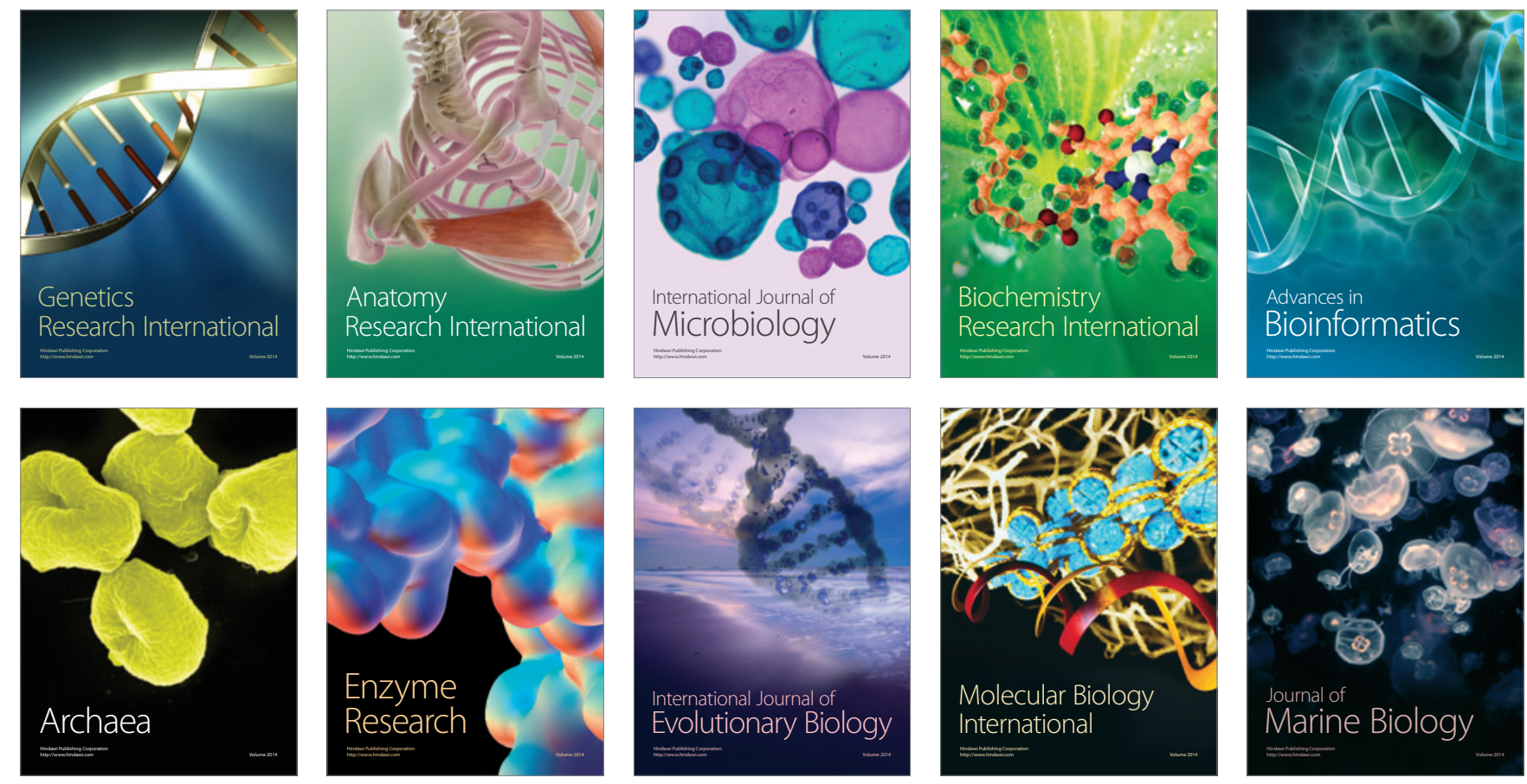